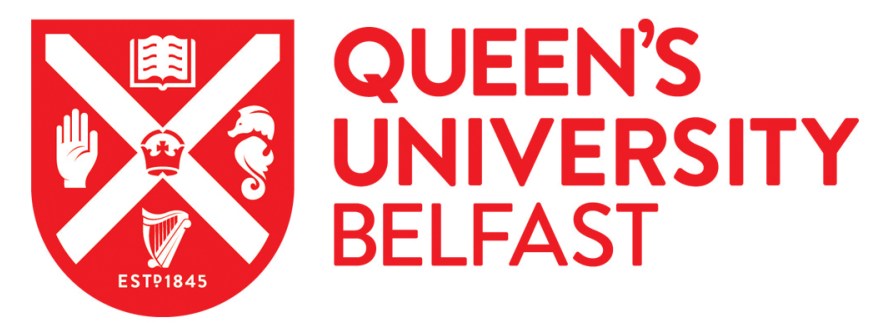

\title{
Compact Low-Profile Antenna for Wireless Medical Vital Sign Monitors at $868 \mathrm{MHz}$
}

Conway, G. A., \& Scanlon, W. G. (2014). Compact Low-Profile Antenna for Wireless Medical Vital Sign Monitors at $868 \mathrm{MHz}$. In Conference Proceedings of the 2014 8th European Conference on Antennas and Propagation $(E u C A P)$ (pp. 830-832). Institute of Electrical and Electronics Engineers Inc..

https://doi.org/10.1109/EuCAP.2014.6901890

Published in:

Conference Proceedings of the 2014 8th European Conference on Antennas and Propagation (EuCAP)

\section{Document Version:}

Peer reviewed version

\section{Queen's University Belfast - Research Portal:}

Link to publication record in Queen's University Belfast Research Portal

\section{Publisher rights}

(c) 2014 IEEE. Personal use of this material is permitted. Permission from IEEE must be obtained for all other uses, in any current or future media, including reprinting/republishing this material for advertising or promotional purposes, creating new collective works, for resale or redistribution to servers or lists, or reuse of any copyrighted component of this work in other works.

\section{General rights}

Copyright for the publications made accessible via the Queen's University Belfast Research Portal is retained by the author(s) and / or other copyright owners and it is a condition of accessing these publications that users recognise and abide by the legal requirements associated with these rights.

Take down policy

The Research Portal is Queen's institutional repository that provides access to Queen's research output. Every effort has been made to ensure that content in the Research Portal does not infringe any person's rights, or applicable UK laws. If you discover content in the Research Portal that you believe breaches copyright or violates any law, please contact openaccess@qub.ac.uk. 


\title{
Compact Low-Profile Antenna for Wireless Medical Vital Sign Monitors at $868 \mathrm{MHz}$
}

\author{
Gareth A. Conway, William G. Scanlon \\ Institute of Electronics, Communications and Information Technology (ECIT), Queen's University Belfast, BT3 9DT, UK. \\ g.conway@qub.ac.uk, w.scanlon@qub.ac.uk
}

\begin{abstract}
A low-profile wearable antenna suitable for integration into low-cost, disposable medical vital signs monitors is presented. Simulated and measured antenna performance was characterized on a layered human tissue phantom, representative of the thorax region of a range of human bodies. The wearable antenna has sufficient bandwidth for the $868 \mathrm{MHz}$ Industrial, Scientific and Medical frequency band. Wearable radiation efficiency of up to $30 \%$ is reported when mounted in close proximity to the novel human tissue phantom antenna testbed at $868 \mathrm{MHz}$.
\end{abstract}

Index Terms-Wearable antenna, propagation, measurement, human tissue phantom.

\section{Introduction}

Real-time wireless monitoring of the human body's vital signs has the potential to transform medical monitoring and reduce the cost of healthcare. In the United States alone, wireless vital signs monitoring devices are forecast to reduce healthcare costs by around $\$ 200$ billion over the next 25 years [1]. Medical Vital Signs Monitors (VSM) continuously monitor the patient. Biosensor data is wirelessly communicated to doctors and nurses via the hospital's IT system. Wearable monitors enable patients to remain mobile, yet facilitate early detection and improved patient care. It is clear that wearable medical systems, such as VSM's need to be comfortable to wear, low size and profile to maintain patient comfort and high efficiency to maintain reliable communications links [2]. Additionally, and vital to the success of these innovations, are that they are ultra-low cost and hence, disposable, to avoid risk of patient infection [3].

In this work, a compact low-profile microstrip patch antenna was developed, suitable for integration into commercial vital signs monitors. The antenna has been designed to be electrically small to conform to the physically constrained VSM systems.

\section{A. Wireless Vital Sign Monitors}

Wireless VSMs measure heart rate, temperature and respiration rate. To do this, they use an impedance harness, which is connected to the skin using conductive electrodes. Broadly, the device incorporates low-power digital processing technology, RF circuitry and an antenna. To fully characterize the performance of the antenna, all system components need to be present. To develop and analyse the performance of wearable antenna designs, a repeatable measurement test-bed was developed. The test-bed is proven to be representative of the actual device environment [4]. In this context, it is electromagnetically representative of the spread in properties that the environment will have on the radio system. The environment for this medical application is the tissue composition of the thorax region of the human population, where the VSM will be attached with conductive electrodes.

\section{B. Wearable Antennas}

Wearable antenna designs with relatively large bandwidths are generally derivatives of dipole and monopole designs. These antennas tend to be planar (2D) structures, not having a ground plane between the radiating element and tissue surface [5]. Although they are low-profile and can be conformal to the surface of the body, they suffer from significant antenna-body coupling and poor radiation efficiency when placed in close proximity to the tissue surface. However, they mitigate against resonant frequency shifts due to their relatively large bandwidth characteristics and can be easily manufactured using single layer printed manufacturing techniques [4]. High performance wearable antennas with optimal radiation efficiency tend to have a groundplane, such as microstrip patch antennas [2]. These antennas generally have a significant height dimension, requiring more than one layer for construction. Wearable microstrip antennas with height dimensions of $5-10 \mathrm{~mm}$ were found to give good performance at $2.45 \mathrm{GHz}$ [2]. MPAs are generally constructed on dielectric substrates with a dielectric spacing media between the radiating element and groundplane. The groundplane, if physically large, can significantly reduce the coupling to the human tissue and thus, reduce resonant frequency shifts and improved radiation efficiency. However, they have relatively narrow bandwidths (high Q-factor). Therefore, wearable designs must be optimized to ensure small deviations in resonant frequency do not result in the antenna having poor radiation characteristics at the frequency band of interest (impedance mismatch losses).

In this work the proposed microstrip antenna (Fig. 1) is comprised of a groundplane with a radiating patch element (40 mm x $22 \mathrm{~mm}$ ) spaced $5 \mathrm{~mm}$ from the ground plane using low permittivity foam. The antenna was prototyped using Rohacell HF51 foam $\left(\varepsilon_{\mathrm{r}}=1.07\right)$ and copper. As the antenna does not require the use of high performance dielectrics, it 
could be manufactured for a low cost, suitable for integration into disposable VSMs.

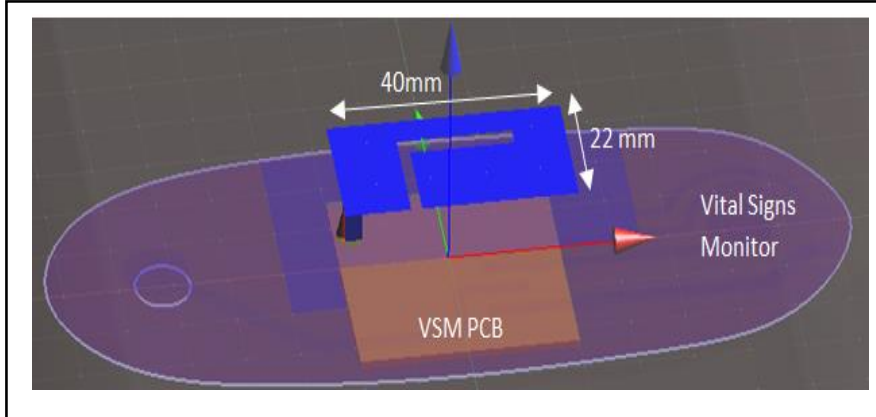

Fig. 1. Numerical Model of the antenna integrated with a vital sign monitor.

\section{Measurement Methodology}

Vital sign monitors used in real-life applications will be required to operate faultlessly on a diverse range of human test-subjects. The physical layer performance of these devices is key to robust and reliable communication links [6]. It is therefore essential that antennas designed for use in these applications, operate on a broad range of tissue composition and morphologies, representative of the actual operating environment. An antenna test-bed which is representative of a broad range of tissue compositions would ideally have variable tissue thicknesses, where the wearable antenna performance bounds could be established. The objective would be to verify that a device operating on any human test subject would fall within the performance bounds as measured on the test-bed. This could be achieved by selecting the optimal tissue thicknesses to give the maxima and minima performance metrics of the antenna, namely, impedance match $\left(s_{11}\right)$ and insitu radiation efficiency.

The proposed phantom concept is a layered tissue design (Fig. 2), based on the geometry of a first generation phantom [2]. The phantom is comprised of three tissue layers, namely, skin, fat and muscle tissue. Physically, the phantom has a solid skin and fat tissue layer with a liquid center layer. The inner layer, representative of subcutaneous adipose tissue (SAT) also acts as a container for the liquid core. The materials are representative of tissue properties in the $800-2500 \mathrm{MHz}$ band. Furthermore, the SAT layer thickness can be adjusted by inserting additional close fitting blocks of SAT material. By adjusting the thickness of the SAT layer, the antenna performance bounds were established. On the Lean-Side (LS) of the phantom, the fat tissue layer was $4 \mathrm{~mm}$. On the ThickSide (TS) of the phantom, the tissue layer representative of fat tissue was $25 \mathrm{~mm}$ thick. These layer thicknesses gave maximum deviation in both return loss and radiation efficiency [4].

\section{A. Simulated Results}

The antennas were designed using SEMCAD-X FDTD numerical modeling software. To evaluate the on-body performance, the antennas were optimized to be resonant at the operating frequency when placed in close proximity to the tissue surface. The return loss as a function of frequency and the in-situ radiation efficiency were used as metrics for antenna performance. Antenna-tissue separation distances of between 5-9 $\mathrm{mm}$ are expected for a VSM patch fixed to the thorax region. The numerical model assumes a uniform separation distance. Fig. 3 shows the 3D phantom mounted radiation pattern of the antenna. The antenna radiation plot shows maximum gain normal to the tissue surface, which is optimal for the off-body propagation channel [7].

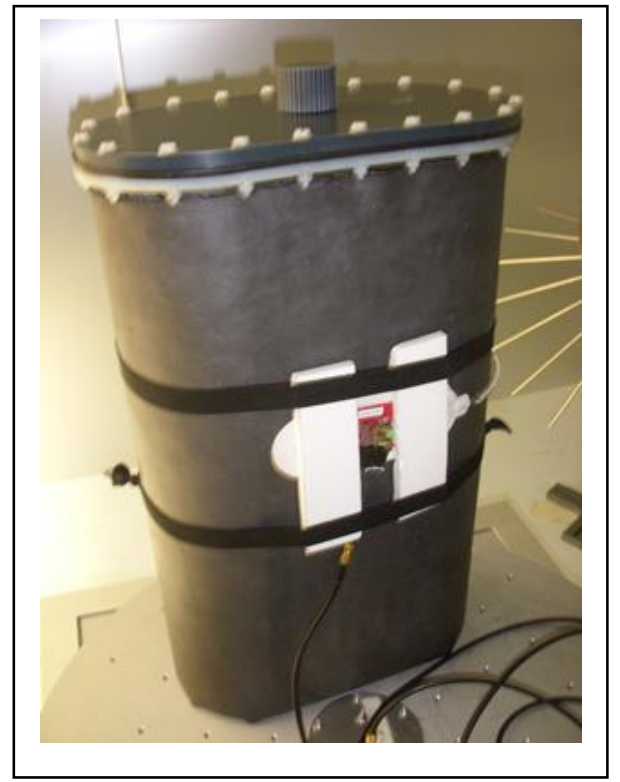

Fig. 2. Layered Human Tissue Phantom with medical vital signs monitor.

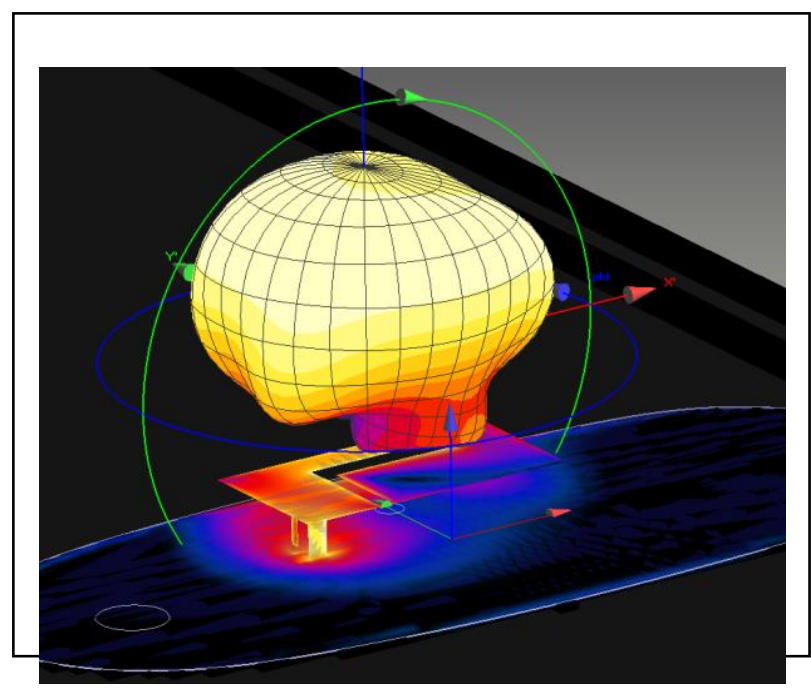

Fig. 3. Simulated far-field radiation pattern with antenna surface current distribution at $868 \mathrm{MHz}$. 


\section{B. Measured Results}

The MPA antenna was prototyped using copper with a Rohacell foam dielectric spacer with permittivity close to air (Fig. 4). The return loss $\left(\mathrm{s}_{11}\right)$ and the radiation efficiency of the VSM antenna were measured on the physical tissue phantom in a Bluetest reverberation chamber, Fig. 5 and Fig. 6, respectively. The antennas were mounted $5 \mathrm{~mm}$ and $9 \mathrm{~mm}$ from the phantom surface using Rohacell foam. Fig. 5 results show that there is a small shift in resonant frequency for the antenna mounted $5 \mathrm{~mm}$ from the Thick-Side (TS) and the Lean-side (LS). There is good agreement between simulated and measured results in that; there was an insignificant shift in resonant frequency between both sides of the phantom. Antenna-tissue decoupling was achieved by optimizing the size and shape of the groundplane between the radiating element and tissue surface. The bandwidth of the antenna in both cases is approximately $10 \mathrm{MHz}$, suitable for the $868 \mathrm{MHz}$ ISM band, which has has a frequency band of $863-870 \mathrm{MHz}$. The prototype antenna resonant frequency can be increased by adjusting the resonant length of the MPA. The measured radiation efficiency results as a function of frequency are presented in Fig. 6. Key results have been extracted and presented in Table I. Table I compares the simulated and measured average (over the $-10 \mathrm{~dB}$ bandwidth of the antenna) radiation efficiency. The antenna maintains relatively high radiation efficiency and is not significantly degraded by proximity to different tissue compositions. The groundplane size has been minimized where possible. Improvements in the radiation efficiency may be achieved by extending the groundplane around the perimeter of the radiating element.

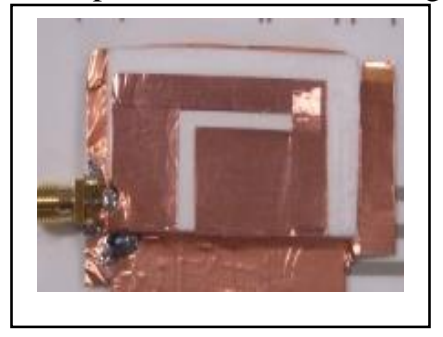

Fig. 4. Lightweight MPA Antenna prototyped using copper with Rohacell foam HF51 dielectric spacer.

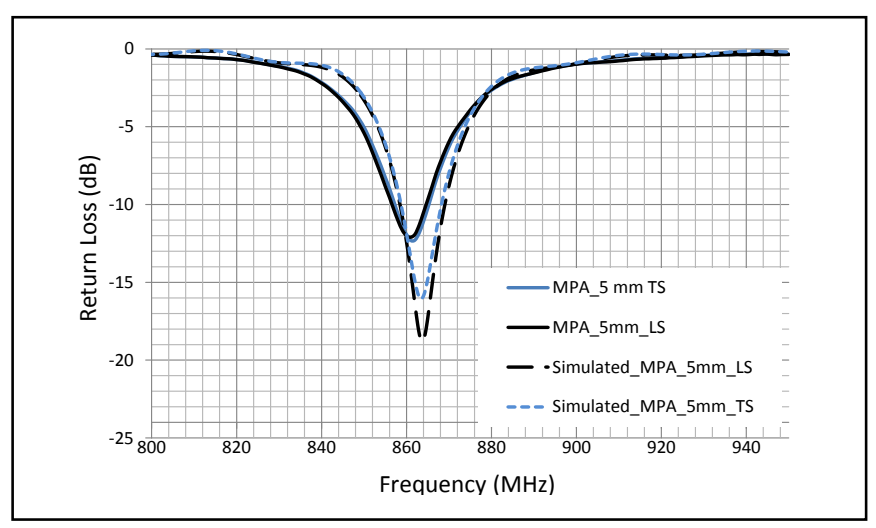

Fig. 5. Simulated vs. Measured return loss for the antenna placed on the Thick-Side and Lean-Side of the phantom.

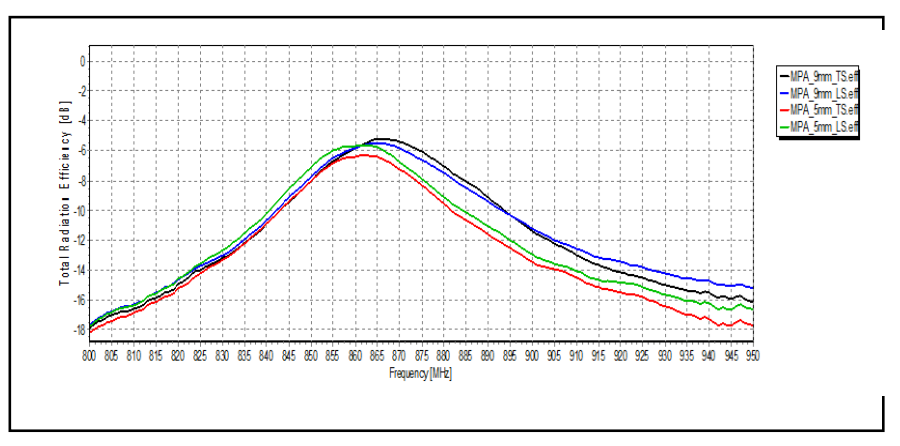

Fig. 6. Measured phantom mounted Radiation Efficiency as a function of frequency when spaced $5 \mathrm{~mm}$ and $9 \mathrm{~mm}$ from phantom surface.

TABLE I. ANTENNA RADIATION EFFICIENCY AT $868 \mathrm{MHZ}$

\begin{tabular}{|l|c|c|}
\hline \multicolumn{3}{|c|}{ Phantom Mounted Radiation Efficiency } \\
\hline \multicolumn{1}{|c|}{ Measurement } & Thin Side & Thick Side \\
\hline Simulated Efficiency & $27 \%$ & $24 \%$ \\
\hline Measured_5 mm Spacing & $30 \%$ & $26 \%$ \\
\hline Measured_9 mm Spacing & $30 \%$ & $30 \%$ \\
\hline
\end{tabular}

\section{Conclusion}

A physically compact antenna suitable for integration into low cost vital signs monitors has been presented. The antenna shows good wearable performance when placed in close proximity to the antenna test-bed phantom. Further antenna impedance optimization is required, to ensure the full impedance bandwidth for the antenna is realized. The antenna maintains its performance as a function of separation distance and tissue composition and is a promising candidate for applications where the wireless system must operate on multiple users.

\section{References}

[1] Center for Technology and Aging Report, www.techandaging.org, May 2013.

[2] G.A. Conway \& W. G. Scanlon, "Antennas for Over-Body-Surface Communication at $2.45 \mathrm{GHz}$," IEEE Trans. Antennas and Prop., 2008.

[3] K. Meehan Arias, 'Contamination and Cross Contamination on Hospital Surfaces and Medical Equipment,' Web Source: www.initiativespatientsafety.org, March 2012.

[4] G. A. Conway, W. G. Scanlon, C. Nunn, A. Burdett, 'Layered RF Phantom Characterisation for Wireless Medical Vital Sign Monitors,' IEEE International Symposium on Antennas and Propagation. 2013.

[5] P.S. Hall and Y. Hao, Antennas and Propagation for Body-Centric Wireless Communications, Artech House Publisher, 2006.

[6] G. A. Conway, S. L. Cotton \& W. G. Scanlon, "An Antennas and Propagation Approach to Improving Physical Layer Performance in Wireless Body Area Networks," IEEE, JSAC Body Area Networks, 31st Jan 2008.

[7] G. A. Conway, W. G. Scanlon \& S. L. Cotton, "The Performance of OnBody Wearable Antennas in a Repeatable Multipath Environment," IEEE Antenna \& Propagation Symposium, San Diego, UK, Jan 2008. 